\title{
Tool wear development in gear skiving process of quenched and tempered internal gears
}

\author{
Tassilo Arndt ${ }^{1}$ (D) $\cdot$ Jan Klose ${ }^{1} \cdot$ Michael Gerstenmeyer ${ }^{1}$. Volker Schulze ${ }^{1}$ \\ Received: 31 March 2021 / Accepted: 14 September 2021 / Published online: 21 October 2021 \\ (c) The Author(s) 2021
}

\begin{abstract}
Gear skiving is a highly productive machining process, especially for manufacturing of high strength internal gears as required for high performance electric drive trains. However, the complex process kinematics cause intense variations of the effective cutting parameters during tool engagement. Thus, particularly the tool must meet high requirements to achieve long tool life at required workpiece quality. These requirements are amplified even more when machining quenched and tempered materials from the massive blank.

In the presented study, the influence of various key factors on the tool wear development in gear skiving process are quantified. In several tests, the cutting speed, workpiece tensile strength, cooling lubricant strategy, as well as the cutting strategy are varied in order to optimize tool life. Therefore, single-tooth tests on quenched and tempered internal gears from 31CrMoV9 (AISI 4340) steel are conducted and wear flank land width evolution of the tools is examined. In addition, the workpiece is evaluated with regard to surface quality. Results reveal that different factor level combinations can have various effects on tool wear characteristics and therefore on tool life. The correlations presented provide recommendations for practical application and contribute to deeper process understanding.
\end{abstract}

\section{Entwicklung des Werkzeugverschleißes beim Wälzschälen von vergüteten Innenverzahnungen}

\section{Zusammenfassung}

Das Wälzschälen ist ein hochproduktives Bearbeitungsverfahren, insbesondere für die Herstellung von hochfesten Innenverzahnungen, wie sie für elektrische Hochleistungsantriebe benötigt werden. Die komplexe Prozesskinematik verursacht jedoch starke Schwankungen der lokal wirksamen Prozesskenngrößen während des Werkzeugeingriffs, sodass insbesondere an das Werkzeug hohe Anforderungen gestellt werden, um eine hohe Standzeit bei geforderter Werkstückqualität zu erreichen. Diese Anforderungen werden bei der Zerspanung von vergüteten Werkstoffen aus dem Vollen noch weiter verstärkt.

In der vorliegenden Studie wird der Einfluss verschiedener Schlüsselfaktoren auf die Entwicklung des Werkzeugverschleißes beim Wälzschälen quantifiziert. In mehreren Versuchen werden die Schnittgeschwindigkeit, die Werkstückzugfestigkeit, die Kühlschmierstrategie und die Schnittstrategie variiert, um die Werkzeugstandzeit zu optimieren. Dazu werden Einzelzahnversuche an vergüteten Innenverzahnungen aus 31CrMoV9 (AISI 4340) durchgeführt und die Entwicklung der Verschleißmarkenbreite der Werkzeuge untersucht. Zudem wird das Werkstück hinsichtlich der gefertigten Oberflächenqualität bewertet. Die Ergebnisse zeigen, dass verschiedene Faktorenkombinationen unterschiedliche Auswirkungen auf das Verschleißverhalten der Werkzeuge und damit auf die Standzeit haben können. Die vorgestellten Korrelationen geben Empfehlungen für die praktische Anwendung und tragen zu einem tieferen Prozessverständnis bei.

Tassilo Arndt

tassilo.arndt@kit.edu

Jan Klose

jan.klose@kit.edu

Michael Gerstenmeyer

michael.gerstenmeyer@kit.edu
Volker Schulze

volker.schulze@kit.edu

1 wbk Institute of Production Science, Department

Manufacturing and Materials Technology, Karlsruhe Institute of Technology, Kaiserstr. 12, 76131 Karlsruhe, Germany 


\section{Introduction}

The highly productive gear skiving process is suitable for manufacturing high-quality internal gears required for planetary gearboxes in electric vehicles [1]. Although the process was patented over 100 years ago, setting economical tool life is still a major challenge in some applications. Intense variations of the effective cutting parameters during tool engagement are caused by the complex process kinematics. Negative rake angles and small clearance angles are typical for the process and often lead to small stable process windows [2]. Therefore, in contrast to other machining processes such as milling, special attention must be paid to those angles. Jansen used uncoated high speed steel tools and cooling lubricant in a gear skiving process to machine internal gears with a tensile strength up to $R_{m}=980 \mathrm{MPa}$ [3] . Tool life increases by a factor of 3 to 5 by reducing cutting speed by $50 \%$. The tool life of tungsten carbide can exceed that of high speed steel by a factor of 6 [4]. Compared to conventional AlTiN based coatings, an AlCrN coating performs with better adhesion and tool life [5]. Reducing the tensile strength of the workpieces by $15 \%$ increases tool life by a factor of 2 to 3 . In general, these tendencies are also accepted for other processes with intermittent cut, e.g. gear hobbing [6]. Process strategies with multiple radial infeeds are also beneficial for tool life [2]. In a theoretical study, Guo et al. demonstrate, that the load distribution on the cutting edge and therefore the wear distribution is additionally depending on the cutting strategy [7]. For example, a combination of radial infeed and rotational offset can lead to high local loads being equalized along the cutting edge. According to Stadtfeld, tool life of coated carbide tools can be extended by omitting cooling lubricant in gear skiving [8]. He assumes, that this is caused by the increased process heat, which decreases the material resistance against deformation in the shear zone.

However, a systematic investigation on tool life of coated carbide tools in dry gear skiving process of high strength materials is absent. This study aims to show the potential of dry gear skiving with carbide tools in comparison to gear skiving with oil lubrication. Therefore, cutting speed and tensile strength of the workpieces are varied. Tool life and surface quality of the manufactured workpieces are targeted. In addition, two alternative process strategies are tried, which are developed based on experimental and theoretical process analysis.

\section{Materials and methods}

The experimental procedure and parameters including workpiece, tool and process correspond directly to the experiments of a previous study at wbk Institute of Production Science, where internal gears made of quenched and tempered steel 31CrMoV9 (AISI 4340) were machined from the massive blank with the use of oil lubricant [5]. This methodology was chosen in order to be able to compare the results directly. The tests were conducted on a skiving machine based on the customized vertical lathe type INDEX V300Sonder [9]. Similar to the previous study [5], the established analogous tool setup with a singletoothed cutting insert was used for the experiments, which allows to map the tool wear evolution at highly reduced workpiece quantity and tool costs [4]. The experimental setup is presented in Fig. 1. As the longest tool life was achieved with carbide tools $\mathrm{K} 30$ with $\mathrm{AlCrN}$ coating in previous experiments [5], this combination was used in this study. Workpiece, tool and process data are listed in Table 1. Experiments marked with "dry machining" have been conducted without the use of fluid cooling lubricant but with pressurized air to ensure proper chip removal.

To estimate the tensile strength $R_{m}$ of the quenched and tempered workpieces, the Vickers hardness was measured on the surface and converted according to DIN EN ISO 18265 [10], see Table 2. Tool wear was measured optically with a light microscope of type Zeiss Stemi SV11 in combination with the software Zeiss Axiovision. For this purpose, pictures were taken from six specified positions of the dismounted cutting inserts representing its actual condition, see Fig. 2. In accordance to previous experiments, a maximum wear flank land width of $\mathrm{VB}_{\max }=60 \mu \mathrm{m}$ was chosen as wear criteria, as the carbide
Fig. 1 Experimental setup with analogous tool and cutting insert

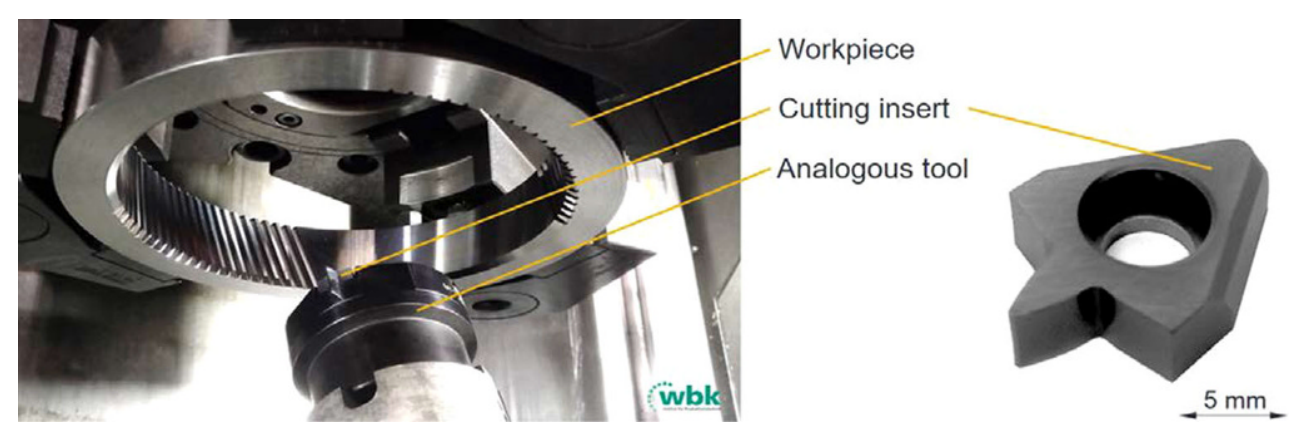


Table 1 Workpiece, tool and process data in accordance to previous experiments [5]

\begin{tabular}{|c|c|c|c|c|c|}
\hline \multicolumn{6}{|l|}{ Workpiece data } \\
\hline Number of teeth & $\mathrm{z}_{2}$ & -96 & Normal pressure angle & $\alpha_{\mathrm{n}}$ & $17.5^{\circ}$ \\
\hline Helix angle & $\beta_{2}$ & $22.5425^{\circ}$ & Normal module & $\mathrm{M}_{\mathrm{n}}$ & $1.34 \mathrm{~mm}$ \\
\hline Tip diameter & $d_{a} 2$ & $135.8 \mathrm{~mm}$ & Generating addendum modification coefficient & $\mathrm{X}_{\mathrm{e}}$ & 0.16546 \\
\hline Root diameter & $\mathrm{d}_{\mathrm{f} 2}$ & $143.2 \mathrm{~mm}$ & Tooth width & $\mathrm{b}_{2}$ & $27.2 \mathrm{~mm}$ \\
\hline \multicolumn{6}{|c|}{ Tool and process data } \\
\hline Number of teeth & $\mathrm{z}_{0}$ & $48(1)$ & Constructive head clearance angle & $\alpha_{c}$ & $0^{\circ}$ \\
\hline Helix angle & $\beta_{0}$ & $0^{\circ}$ & Constructive head rake angle & $\gamma_{c}$ & $0^{\circ}$ \\
\hline Tip diameter & $\mathrm{d}_{\mathrm{a} 0}$ & $68.68 \mathrm{~mm}$ & Stair angle & $\tau$ & $0^{\circ}$ \\
\hline Root diameter & $\mathrm{d}_{\mathrm{f} 0}$ & $60.4 \mathrm{~mm}$ & Axis crossing angle & $\Sigma$ & $24.75^{\circ}$ \\
\hline Substrate & - & K30 & Position angle & $\mathrm{K}_{2}$ & $25.9^{\circ}$ \\
\hline Coating & - & $\mathrm{AlCrN}$ & Rake offset & $\mathrm{e}$ & $44.67 \mathrm{~mm}$ \\
\hline
\end{tabular}

inserts presented rapidly progressing breakage beyond this point [5]. The rake faces of the inserts were also examined using a Nanofocus confocal microscope and $\mu$ soft software analysis. The flank roughness of the manufactured workpieces was quantified by of Mahr MarSurf XCR 20. Parts machined by worn tools were measured before the wear criterion was exceeded.

The local process parameters are assessed with the help of geometric penetration calculation implemented in a cross-process simulation environment at wbk Institute for Production Science. Therefore, the process-specific kinematics are prepared in a pre-processing stage and transferred to a universal calculation core, where the local effective process parameters are determined. A detailed description of the methodology of the calculation core can be found in [11]. With the help of the simulation environment, two alternative process strategies were developed in order to analyze the influence of changes in local cutting parameters on the appearing wear phenomena, see Fig. 3 and Table 3. Strategy A was applied in the previous experiments [5], which is why it is used as reference. In process design, the maximum cutting thickness at the tool tip were kept in a range of $0.09 \mathrm{~mm}<\mathrm{h}_{\max }<0.12 \mathrm{~mm}$ for all tool passes, which is why the axial feed $s_{a x}$ increases with the tool pass, see Table 3. Strategies B and C are alternatives evaluated only in single experiments. Their theoretical background is descripted in Sect. 3. In contrast to strategy $\mathrm{B}$, strategy $\mathrm{C}$ is tested at higher tensile strength due to limited workpieces of each batch.
Fig. 2 Positions of interest, which are analyzed by light microscopy. Tool after 1,018 manufactured gaps, $R_{m}=1,200 \mathrm{MPa}$, $\mathrm{v}_{\mathrm{c}}=140 \mathrm{~m} / \mathrm{min}$, dry process, strategy A

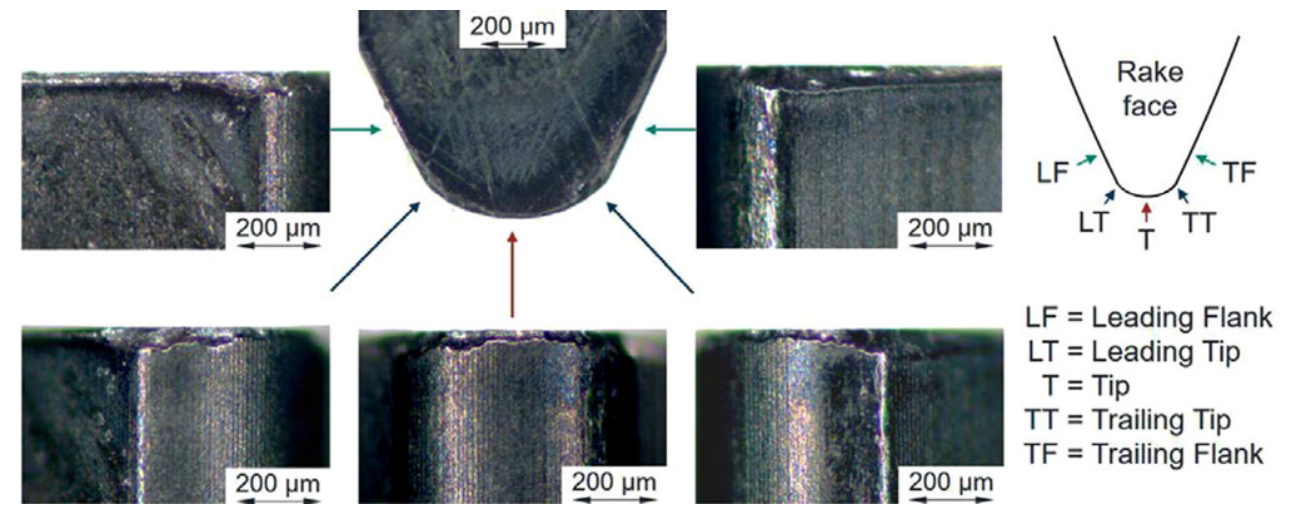

b
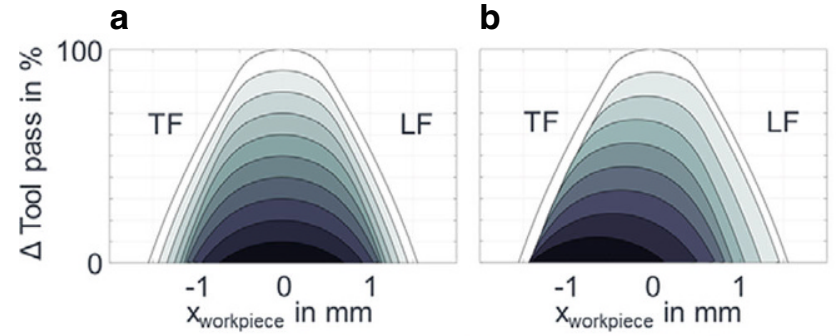

C

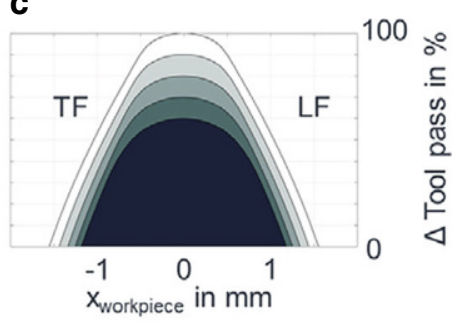

Last tool pass

First tool pass 
Table 2 Workpiece strength classes, Vickers hardness and converted tensile strength

\begin{tabular}{lll}
\hline Strength class & Vickers hardness & $\begin{array}{l}\text { Converted tensile strength } \\
\mathrm{R}_{\mathrm{m}}\end{array}$ \\
\hline $1,200 \mathrm{MPa}$ & 376 & $1,175 \mathrm{MPa} \pm 31 \mathrm{MPa}$ \\
& $\mathrm{HV} 30 \pm 10 \mathrm{HV} 30$ & \\
$1,400 \mathrm{MPa}$ & 452 & $1,413 \mathrm{MPa} \pm 19 \mathrm{MPa}$ \\
& $\mathrm{HV} 30 \pm 6 \mathrm{HV} 30$ & \\
\hline
\end{tabular}

\section{Results and discussion}

Abrasive wear is the dominating effect when dry machining workpieces of lower strength $\mathrm{R}_{\mathrm{m}}=1,200 \mathrm{MPa}$, see Fig. 2 . A uniform flank wear develops linearly and finally determines tool life on the TF, see Fig. 4. No breakouts or visible cracks appear, resulting in superior tool life. Wear also develops linearly but more steeply in the wet process. Here, tool life is limited by localized breakouts, see Fig. 4. Regardless of the cooling strategy, fatal breakouts and therefore tool failure occur almost unpredictably when machining workpieces of higher strength $R_{m}=1,400 \mathrm{MPa}$. Slight increases in wear at the begin are followed by rapid breakouts, which are delayed only a little in the dry process, see Fig. 4. For all cutting speeds investigated, a characteristic deepening on the rake face near the cutting edge was observed prior to total tool failure, see Fig. 5. This deepening reminds of crater wear and is typically located in the transition area of $\mathrm{T}$ and LT. It is probably the starting point of cracks, which lead to fatal breakouts, see Fig. 5c.

Crater wear is typical for high speed steel tools and seldom described for carbides. However, crater wear has been observed in dry gear hobbing with $\mathrm{AlCrN}$-coated carbide tools [6]. But the crater wear and fractures occurred at significantly increased cutting speeds $\left(\mathrm{v}_{c}>600 \mathrm{~m} / \mathrm{min}\right)$, while abrasive wear was the dominating mechanism for more conservative process parameters. The fact that crater wear occurs at medium cutting speeds in gear skiving raises the question which conditions lead to the heavily increased tool loads in this process. A possible explanation for the differences in the dominant tool wear mechanism comparing dry and wet processes is the strong heating of the cutting edge during tool engagement. According to Stadtfeld, the increased process heat decreases the resistance against deformation of the chip in the shear zone [8]. As known from milling, this temperature dependent softening effect reduces cutting forces and thus tool load [12]. Besides the higher temperatures in the shear zone, the tool as a whole also reaches higher temperatures. Simultaneously, the tool is not cooled down by the cooling lubricant at high rates between tool engagements. This leads to smaller temperature gradients and therefore to lower thermomechanical stress in the tool. This helps to avoid cracks or at least slows down propagation. The softening effect and the effect of lower thermomechanical stresses probably appear in combination. However, there is currently no indication which of them is the dominant one. Analysis of the motor spindle power seem to support decreasing forces but still remain inconclusive. In effect, further investigations will have to be undertaken to definitively explain the dominant mechanisms.

Longest tool life is achieved when workpieces of lower strength are machined dry at a cutting speed of $v_{c}=140 \mathrm{~m} / \mathrm{min}$, see Fig. 4. Here, tool life is limited by the wear on the trailing flank (TF). For this reason, strategy B is designed to relieve the TF by combining radial infeed with rotational offset, as proposed by Guo et al. [7]. Thus, the leading flank (LF) is mainly cutting in case of strategy B, see Fig. $6 \mathrm{~b}$. While the maximum chip thickness $\mathrm{h}_{\max }$ at the tool tip $\mathrm{T}$ is kept constant, it slightly increases on the LF, see Fig. 6a. The minimum rake angle $\gamma_{\min }$ decreases a bit in this area, see Fig. $6 \mathrm{~b}$. The minimum clearance angles $\alpha_{\text {min }}$ are almost not affected and locally drop below zero at the transition area between flank and tip (positions TT and LT, see Fig. 6c). As negative clearance angles indicate collision and are therefore critical for tool wear, strategy $\mathrm{C}$ is designed to ensure positive clearance angles. Unfortunately, due to the given tool geometry, this can only be achieved in conjunction with strongly decreased minimal rake angles at the tool tip $\mathrm{T}$ and on the LF.

Tool life before exceeding the wear criteria is compared for different cooling strategies, workpiece strength, cutting speeds and process strategies, see Fig. 7. As expected, tool life is generally exceeded when dry machining workpieces with lower tensile strength. Reducing the strength by $15 \%$

Table 3 Feeds of the applied process strategies, axial feed $\mathrm{sax}_{\mathrm{x}}$ in $\mathrm{mm}$ per workpiece rotation

\begin{tabular}{|c|c|c|c|c|c|c|c|c|c|c|c|}
\hline \multirow{2}{*}{\multicolumn{2}{|c|}{ Strategy }} & \multicolumn{10}{|c|}{ Tool pass no } \\
\hline & & 1 & 2 & 3 & 4 & 5 & 6 & 7 & 8 & 9 & 10 \\
\hline \multirow[t]{2}{*}{$\overline{\mathrm{A}}$} & Radial infeed in $\%$ & 10 & 10 & 10 & 10 & 10 & 10 & 10 & 10 & 10 & 10 \\
\hline & $\mathrm{S}_{\mathrm{ax}}$ in $\mathrm{mm} / \mathrm{wr}$ & 0.30 & 0.30 & 0.30 & 0.35 & 0.35 & 0.40 & 0.42 & 0.42 & 0.42 & 0.42 \\
\hline \multirow[t]{2}{*}{ B } & Radial infeed in $\%$ & 12 & 11 & 11 & 11 & 11 & 11 & 11 & 11 & 11 & - \\
\hline & $\mathrm{S}_{\mathrm{ax}}$ in $\mathrm{mm} / \mathrm{wr}$ & 0.30 & 0.30 & 0.30 & 0.25 & 0.35 & 0.40 & 0.42 & 0.42 & 0.42 & - \\
\hline \multirow[t]{2}{*}{$\mathrm{C}$} & Radial infeed in $\%$ & 60 & 10 & 10 & 10 & 10 & - & - & - & - & - \\
\hline & $\mathrm{S}_{\mathrm{ax}}$ in $\mathrm{mm} / \mathrm{wr}$ & 0.10 & 0.42 & 0.42 & 0.42 & 0.42 & - & - & - & - & - \\
\hline
\end{tabular}


Fig. 4 Tool wear evolution for machining with a cutting speed of $\mathrm{v}_{\mathrm{c}}=140 \mathrm{~m} / \mathrm{min}$ in wet and dry condition with process strategy A. Data regarding oil lubrication is taken from [5]

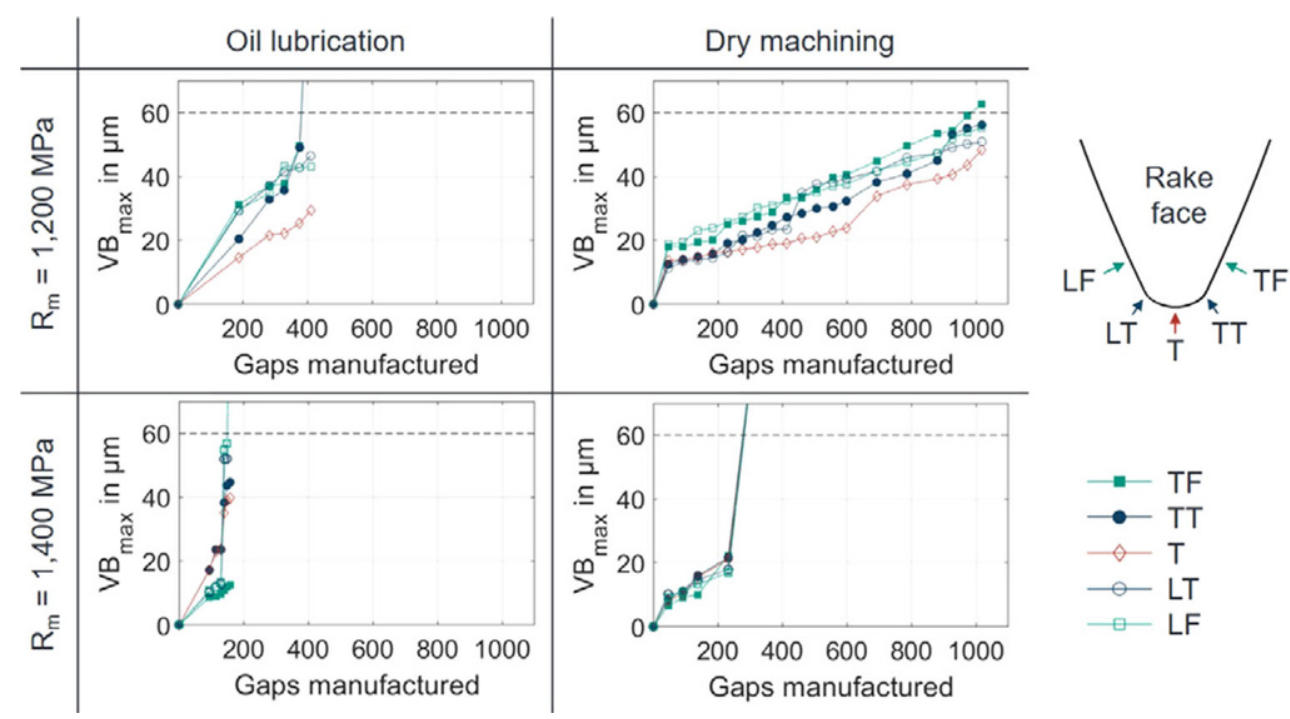

resulted in an increase of the tool life by a factor of 3 to 6 . This means that the benefit is even greater than in the wet process, where a factor of 2 to 3 was obtained [5]. In accordance with the literature, for machining with oil lubrication, tool life increases steadily with decreasing cutting speeds [3]. However, this is not the case for dry machining in the interval of $120 \mathrm{~m} / \mathrm{min}<\mathrm{v}_{\mathrm{c}}<140 \mathrm{~m} / \mathrm{min}$. Here, tool life increases with increasing cutting speed, see Fig. 7. The tendency is clear only for the lower strength. Again the softening effect would be an acceptable explanation, as rising cutting speeds lead to rising temperatures and therefore, to decreasing cutting forces [12]. In this way, local tool life optima in dry gear hobbing have been explained [13].
Since tool life does not significantly differ at cutting speeds of $\mathrm{v}_{\mathrm{c}}=100 \mathrm{~m} / \mathrm{min}$ and $\mathrm{v}_{\mathrm{c}}=140 \mathrm{~m} / \mathrm{min}$ in case of workpieces with higher strength, the question arises, which other variables influence the softening effect. Regarding productivity, increasing the cutting speed by $40 \%$ without a significant drop in tool life is certainly appealing.

The alternative process strategies were developed in order to analyze how the appearing wear phenomena are influenced by changes in local cutting parameter. None of them offers any advantages in terms of tool life, see Fig. 7. While tool life was limited by the flank wear on the TF using strategy A, strategy B was designed to relive this area of the tool. The results show, that the intended effect
Fig. 5 Local deepening on the rake face preliminary to fatal tool failure, $\mathrm{R}_{\mathrm{m}}=1,400 \mathrm{MPa}$, $\mathrm{v}_{\mathrm{c}}=140 \mathrm{~m} / \mathrm{min}$, dry process, strategy A. a 276 gaps manufactured b 276 gaps manufactured c 296 gaps manufactured a

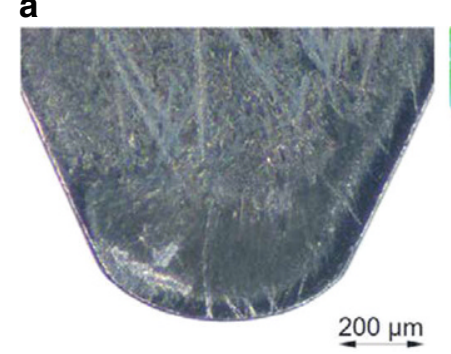

b
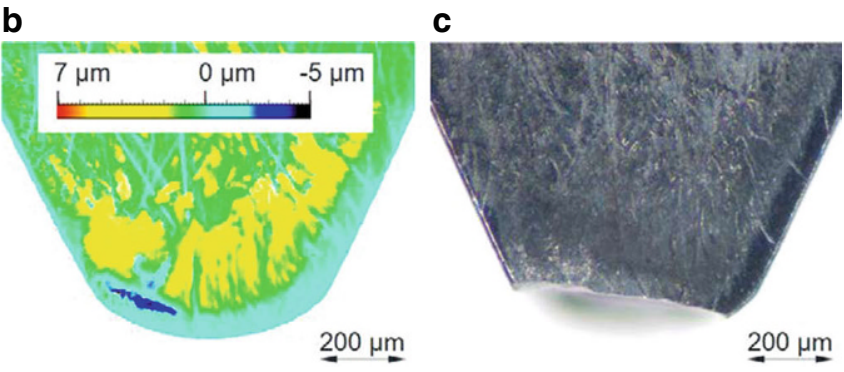

Fig. 6 Main process parameters of the strategies. Profiles are composed of extreme values to be independent of single tool passes
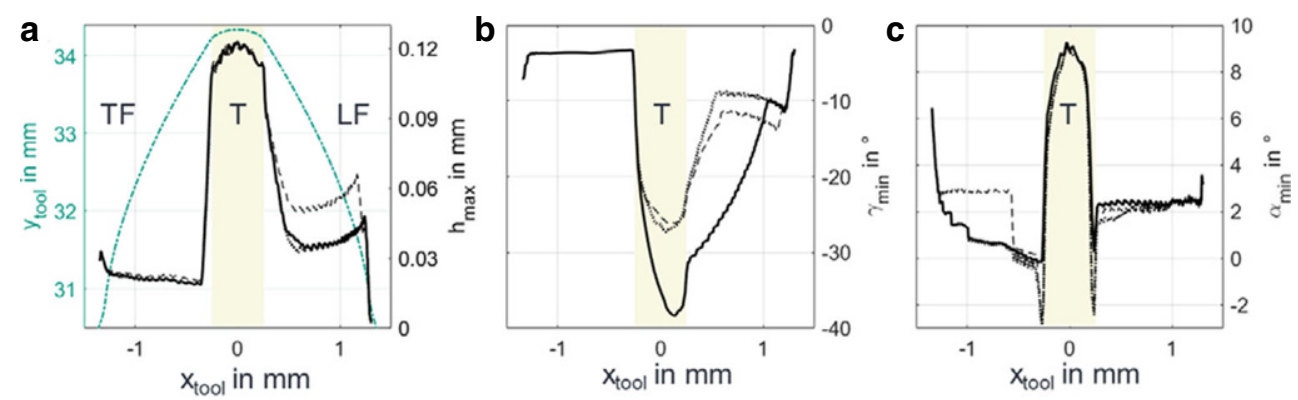

-Toolprofile -......... Strategy A - - - Strategy B - Strategy C 
Fig. 7 Tool life before exceeding a wear criteria of $\mathrm{VB}_{\max }=60 \mu \mathrm{m}$. Values shown without error bar were quantified only once. Data regarding oil lubrication is taken from [5]

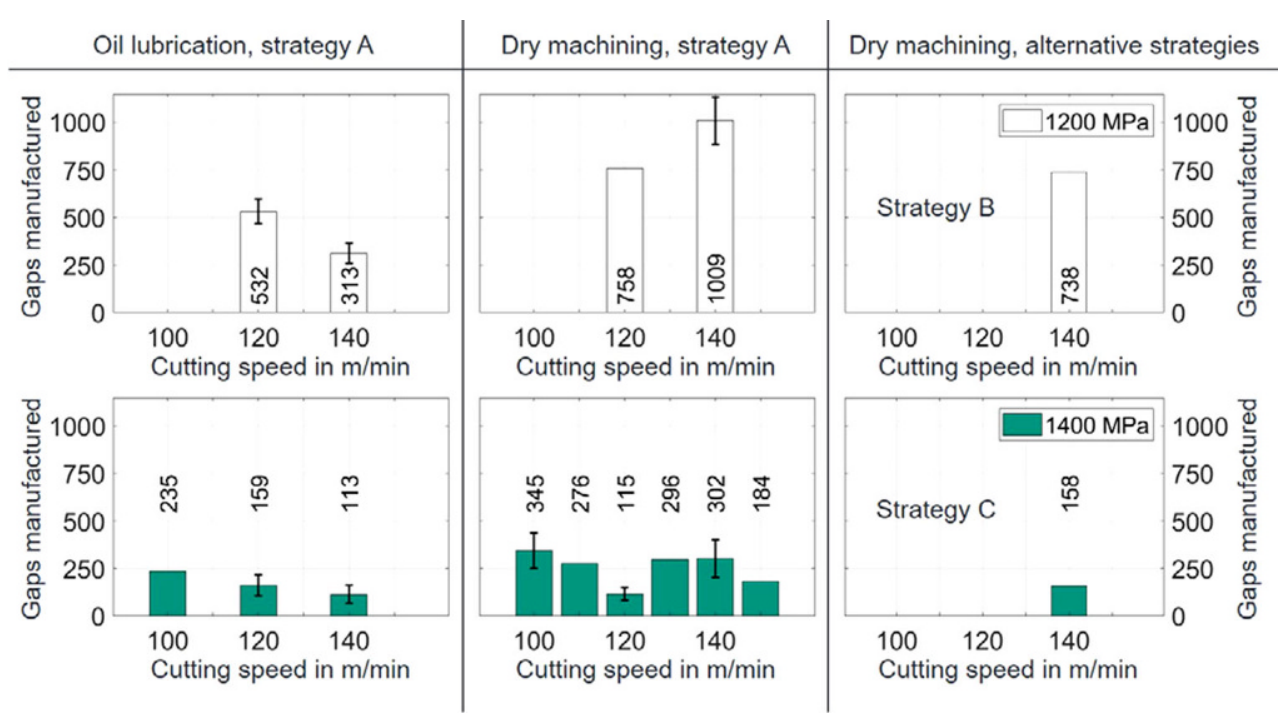

Fig. 8 Tool wear development for machining strength class $\mathrm{R}_{\mathrm{m}}=1,200 \mathrm{MPa}$ in dry condition with different process strategies
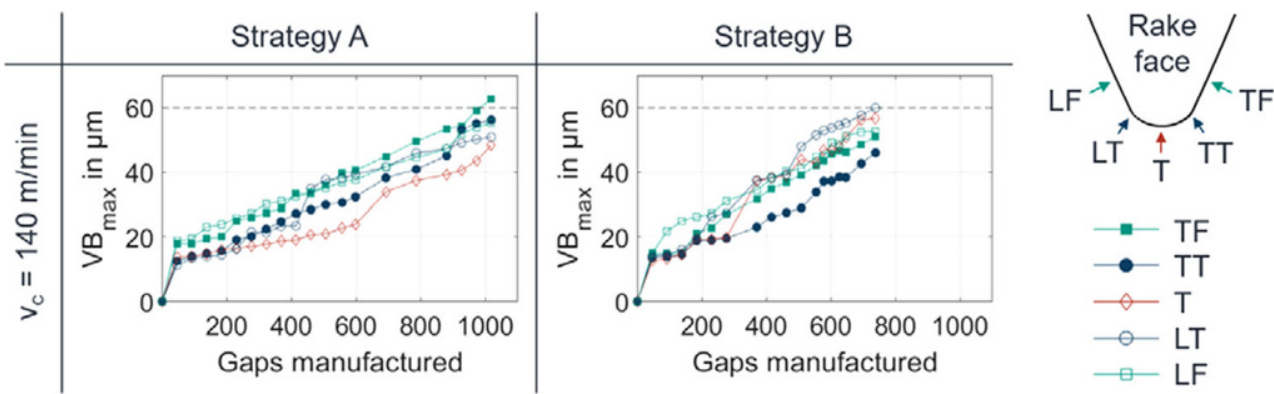

was achieved, as it is no longer determining tool life, see Fig. 8. To this extent, the theoretical results of Guo et al. can be confirmed [7]. However, increasing the maximum chip thickness and decreasing the minimal rake angle on the LF did not only add strain here. In particular, the slope of wear development at the tool tip $\mathrm{T}$ rises considerably, although the main local process parameters did not change much at this point, see Fig. 6 .

As the profiles of the main process parameters shown in Fig. 6 are composed of extreme values, changes in the characteristics of single tool passes cannot be determined from them. Detailed analysis reveals, that the maximum chip thickness variation $\Delta \mathrm{h}_{\max }$ between single tool passes is increased in the area of the tool tip T in case of strategy B, see Fig. 9. This may influence the wear evolution at this point.

In case of strategy $\mathrm{C}$, the wear pattern observed differs considerably from that obtained from strategy A. A breakout on the LF ends the tool life, see Fig. 10a. However, even after the end of tool life, no crater wear can be detected on the rake face, but is already found for strategy A at a similar stage and half its tool life, see Fig. 10b,c. Thus, it is suggested that crater wear of carbide tools is directly related to higher but still negative minimal local rake angle in combination with negative local clearance angles, which cause collision and therefore compression of the tool.

The use of the analogous tool setup resulted in an overall good surface quality, see Fig. 11. This is caused by the ideal cutting conditions, as the analogous tool setup does not exhibit typical tool deviations like pitch errors. There is no evident advantage of wet or dry machining in terms of flank roughness when manufacturing workpieces with new tools. Also, there is almost no difference between TF and LF. Taking into account the standard deviations, the rough ness generally increases with tool wear. However, there are major differences for workpieces of lower strength manufactured with worn tools. While in general the flank roughness worsens only slightly in the wet process, the flank roughness increases by a factor of about 3 on the LF in the dry process. For the TF, the factor is a little lower. The also highly increasing standard deviations indicate more variation in machining conditions. In case of dry machining, the much longer tool life is to be taken into account when assessing the decrease in surface quality. The slight change of roughness for high strength workpieces can be explained by the short observation time. Since the tools fail abruptly with only slight formation of abrasive wear, the effect of tool wear on the surface quality of the last workpiece manufactured before tool failure is low. 
Fig. 9 Maximum chip thickness and its variation for single tool passes
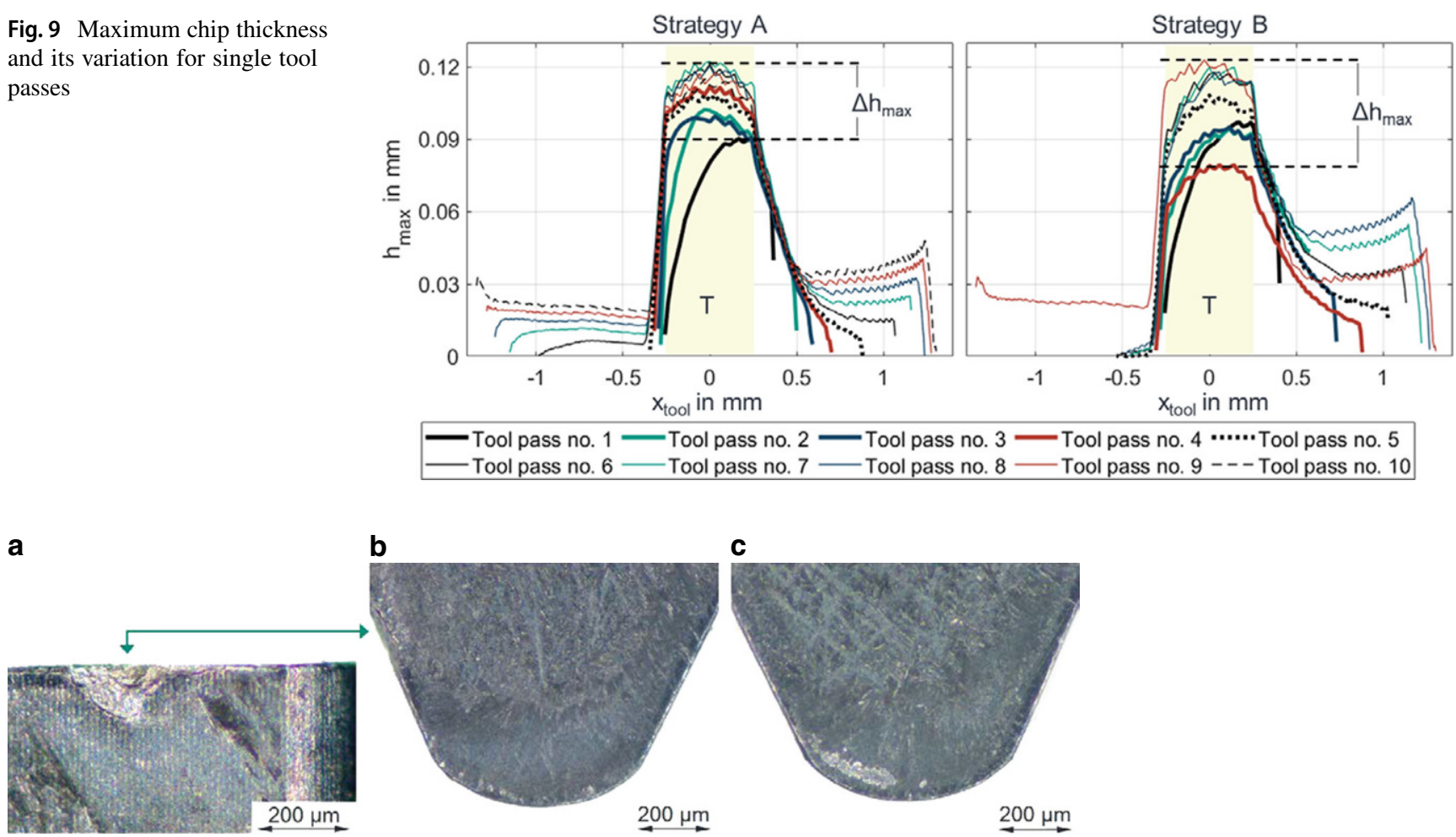

Fig. 10 Different wear characteristics for machining strength class $R_{m}=1,400 \mathrm{MPa}$ in dry condition applying different process strategies with a cutting speed of $v_{c}=140 \mathrm{~m} / \mathrm{min}$. a LF-Strategy C 172 gaps manufactured b Rake face-Strategy C 172 gaps manufactured $\mathbf{c}$ Rake face-Strategy A 138 gaps manufactured

Fig. 11 Flank surface roughness of the manufactured workpieces. All workpieces were machined using strategy A. Data regarding oil lubrication is taken from [6]

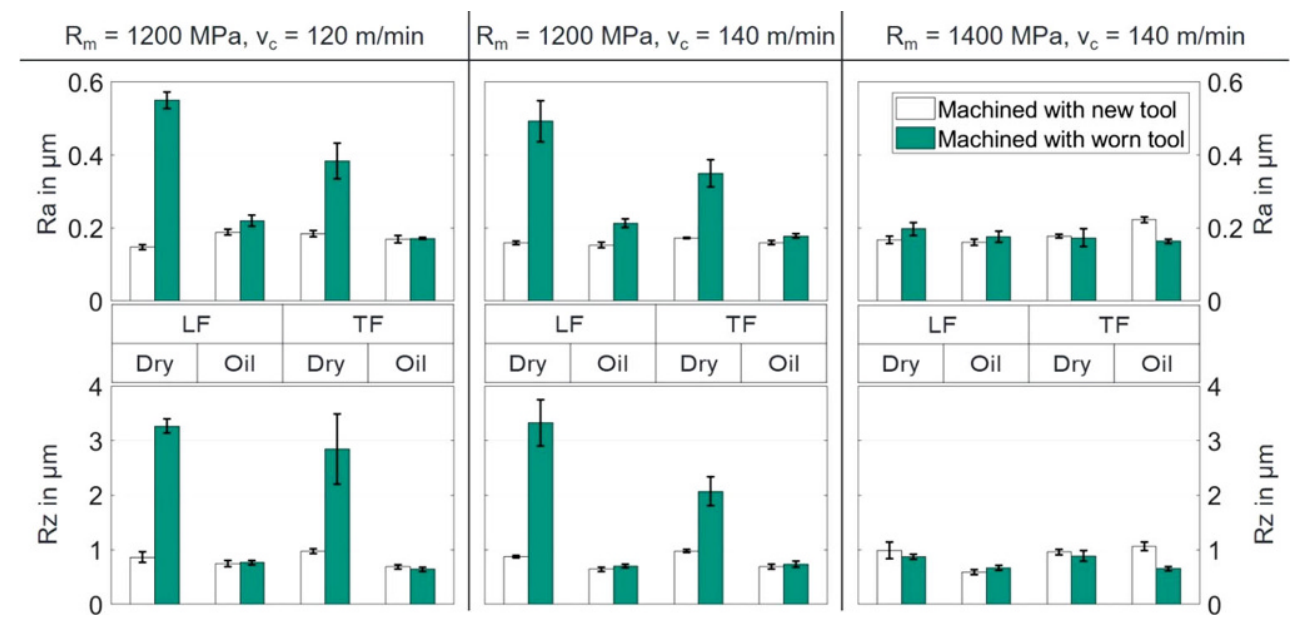

\section{Conclusions}

In the present study, tool wear and surface quality of the manufactured workpieces has been investigated in dry gear skiving process. The following conclusions can be drawn:

- Dry gear skiving shows potential to significantly extend tool life compared to machining with oil lubrication. Due to a change in the dominant wear phenomena when dry machining workpieces with lower tensile strength
$\mathrm{R}_{\mathrm{m}}=1,200 \mathrm{MPa}$, tool life was increased by a factor of 1.5 up to 3 . For workpieces with higher tensile strength $\mathrm{R}_{\mathrm{m}}=1,400 \mathrm{MPa}$, tool life generally increases by about 50 to $150 \%$ depending on the cutting speed.

- Due to the specific dominant wear phenomena such as breakouts and crater wear, gear skiving workpieces with higher tensile strength $R_{m}=1,400 \mathrm{MPa}$ is much more challenging regarding tool and process design. Correlations known from other processes with intermittent cut cannot be transferred directly since local tool life 
optima may exist. For example, increasing the cutting speed by $40 \%$ did not lead to a significant reduction in tool life, opening up significant potential for productivity optimization.

- Tool life and surface quality should always be considered in combination. While there is no evident advantage of wet or dry machining when starting with new tools, a significant increase in roughness is to be expected in case of dry machining till the end of tool life. The use of lubricant only in the finishing tool pass should be tested in the future.

- Geometric penetration calculation is an effective method to assess and specifically manipulate local process parameter. The potential to influence the appearing wear phenomena by adapting the infeed strategy and thus rake and clearance angles was demonstrated. However, optimization of tool life and productivity requires a deep analysis of local cutting conditions in each tool pass and a balancing of the interacting relevant parameters.

- Significantly different wear phenomena raise the question, to what extend findings regarding tool substrate and coating can be transferred from the wet to the dry gear skiving process. Moreover, the wear mechanisms under the specific and challenging conditions of gear skiving and how they are influenced is not yet understood in detail. Thus, further research should be conducted in this area.

Funding Open Access funding enabled and organized by Projekt DEAL.

Conflict of interest T. Arndt, J. Klose, M. Gerstenmeyer and V. Schulze declare that they have no competing interests.

Open Access This article is licensed under a Creative Commons Attribution 4.0 International License, which permits use, sharing, adaptation, distribution and reproduction in any medium or format, as long as you give appropriate credit to the original author(s) and the source, provide a link to the Creative Commons licence, and indicate if changes were made. The images or other third party material in this article are included in the article's Creative Commons licence, unless indicated otherwise in a credit line to the material. If material is not included in the article's Creative Commons licence and your intended use is not permitted by statutory regulation or exceeds the permitted use, you will need to obtain permission directly from the copyright holder. To view a copy of this licence, visit http://creativecommons.org/licenses/by/4. $0 \%$

\section{References}

1. Stadtfeld HJ (2020) Introduction to electric vehicle transmissions. Gear Technol 37(7):42-50

2. Bauer R (2018) Modellbasierte Auslegung von Mehrschnittstrategien beim Wälzschälen. Dissertation, Technical University Chemnitz

3. Jansen W (1980) Leistungssteigerung und Verbesserung der Fertigungsgenauigkeit beim Wälzschälen von Innenverzahnungen. Dissertation, RWTH Aachen, Aachen

4. Bechle A (2006) Beitrag zur prozesssicheren Bearbeitung beim Hochleistungsfertigungsverfahren Wälzschälen. Dissertation, wbk Institute of Production Science, Karlsruhe

5. Schulze V (2019) Untersuchung von Schneidstoffen und Prozessparametern für das Fertigungsverfahren Wälzschälen von hochfesten Innenverzahnungen - Schlussbericht zu IGF-Vorhaben Nr. 19076N, wbk Institute of Production Science, Karlsruhe. https://edocs.tib. eu/files/e01fn20/1690623705.pdf. Accessed: 15 March 2021

6. Karpuschewski B, Beutner M, Köchig M, Wengler M (2017) Cemented carbide tools in high speed gear hobbing applications. CIRP Ann Manuf Technol 66:117-120

7. Guo Z, Mao S, Huyan L, Duan D (2018) Research and improvement of the cutting performance of skiving tool. Mech Mach Theory $120: 302-313$

8. Stadtfeld HJ (2014) Power skiving of cylindrical gears on different machine platforms. Gear Technol 31(1):52-62

9. Hühsam A (2006) Modellbildung und experimentelle Untersuchung des Wälzschälprozesses. Dissertation, wbk Institute for Production Science, Karlsruhe

10. DIN EN ISO 18625 (2014) Metallic materials - Conversion of hardness values (ISO 18265:2013), Berlin

11. Hilligardt A, Böhland F, Klose J, Gerstenmeyer M, Schulze V (2021) A new approach for local cutting force modelling enabling the transfer between different milling conditions and tool geometries. In: 18th CIRP Conference on Modeling of Machining Operations, June 15-17, Ljubljana, 2021

12. Uhlmann $E$, Rasper $P$ (2011) Influences on specific cutting forces and their impact on the stability behavior of milling processes. Prod Eng 5:175-181

13. Sari D, Klocke F, Löpenhaus C (2015) Gear finish hobbing: potentials of several cutting materials. Prod Eng 9:367-376 